\title{
Makna Teologis Dangding Kinanti Ngahurun Balung Karya Haji Hasan Mustapa: Analisis Hermeneutika Paul Ricoeur
}

\author{
Ilham Maulana \\ Jurusan Aqidah dan Filsafat Islam \\ Fakultas Ushuluddin UIN Sunan Gunung Djati Bandung, Indonesia \\ Ilhamm343@gmail.com
}

\begin{abstract}
The purpose of this study was to analyze the theological meaning of Dangding Kinanti Ngahurun Balung by using Paul Ricoeur's hermeneutical analysis. The method used is a type of qualitative research with literature study. The results and discussion of this research include the biography of Haji Hasan Mustapa, the text of Dangding Kinanti Ngahurun Balung and analysis of the theological meaning of Dangding Kinanti Ngahurun Balung. The conclusion of this study is that the theological meaning of Dangding Kinanti Ngahurun Balung is aware of the limitations in the quest to know God, so that humans are required to be humble before God and surrender to Him as a servant. This research is recommended for further studies on Haji Hasan Mustapa's dangding texts and the use of hermeneutics as an analytical tool, especially Paul Ricoeur's hermeneutics and studies on theology.
\end{abstract}

Keywords: Dangding, Hermeneutics, Theological.

\begin{abstract}
Abstrak
Tujuan penelitian ini adalah untuk menganalisis makna teologis dangding Kinanti Ngahurun Balung dengan menggunakan analisis hermeneutika Paul Ricoeur. Metode yang digunakan adalah jenis penelitian kualitatif dengan studi literatur. Adapun hasil dan pembahasan penelitian ini meliputi biografi Haji Hasan Mustapa, teks dangding Kinanti Ngahurun Balung dan analisis makna teologis dangding Kinanti Ngahurun Balung. Kesimpulan penelitian ini adalah makna teologis dangding Kinanti Ngahurun Balung menyadarkan akan keterbatasan dalam pencarian untuk mengetahui Tuhan, sehingga manusia dituntut rendah diri di hadapan Tuhan dan pasrah kepada-Nya sebagai seorang hamba. Penelitian ini direkomendasikan untuk adanya kajian lebih lanjut mengenai teks-teks dangding Haji Hasan Mustapa dan penggunaan hermeneutika sebagai alat analisis,
\end{abstract}


terutama hermeneutika Paul Ricoeur serta kajian-kajian tentang teologi.

Kata kunci: Dangding, Hermeneutika, Teologis.

\section{Pendahuluan}

Permasalahan teologis dalam Islam merupakan hal yang sangat sentral dan fundamen. Karena secara historis, perdebatan teologi atau kalam memiliki permasalahan yang sangat kompleks. Berbagai perdebatan yang terjadi telah memunculkan golongan-golongan teologi atau kalam dalam Islam, setiap aliran atau golongan tersebut memiliki klaim kebenaran terhadap pemikiran yang diusung mengenai setiap permasalahan teologi termasuk tentang masalah ketuhanan (Hanafi, 2015). Haji Hasan Mustapa (selanjutnya HHM) sosok sufi besar dari tanah Pasundan menulis dangding bernuansa mistisisme Islam dan kesundaan (Rohmana, 1991). HHM telah menulis sekitar 10.000-an bait dangding, sedangkan dangding yang dijadikan objek penelitian dalam penulisan ini berjudul Kinanti Ngahurun Balung. Berdasarkan fakta tersebut, HHM nampaknya memiliki pemikiran teologis di dalam karya-karya yang telah dihasilkannya tersebut. Karena jarak waktu yang cukup jauh, perlu kiranya dangding Kinanti Ngahurun Balung ini dimaknai kembali. Terutama dalam konteks teologi. Maka di dalam penelitian ini, penulis hendak mencari makna teologis yang terdapat di dalam teks dangding Kinanti Ngahurun Balung (Asura, 2020).

Dari beberapa penelitian sebelumnya, lebih banyak menyoroti nilai sastra dan tasawuf yang dikandung di dalam dangding HHM. Karena HHM lebih dikenal sebagai tokoh sufi dan juga pujangga, ketimbang teolog. Terlihat dari penelitian yang dilakukan oleh Jajang A. Rohmana "Pembacaan Dangding Haji Hasan Mustapa terhadap Sastra Sufistik Sunda di Era Budaya Populer," juga Jajang A. Rohmana "Tasawuf Sunda dan Warisan Islam Nusantara: Martabat Tujuh dalam Dangding Haji Hasan Mustapa (1852-1930)," Jajang Jahroni "Menemukan Haji Hasan Mustapa (1852-1930)," Hawe Setiawan "Dangding Mistis Haji Hasan Mustapa," Ahmad Gibson AlBustomi "Eksistensi Manusia menurut KH. Hasan Mustapa," dan penelitipeneliti lainnya. Beberapa penelitian yang sudah disebutkan sebelumnya, lebih pada aspek sastra dan pemikiran tasawuf HHM. Sementara penulis mencoba untuk menguak makna teologis yang terdapat di dalam dangding HHM, terutama dangding Kinanti Ngahurun Balung.

Berangkat dari sana, penulis berasumsi bahwa masih sangat jarang yang meneliti dangding HHM di dalam muatan pemikiran teologis yang dikandung di dalamnya, terutama yang terdapat dalam dangding Kinanti Ngahurun Balung. Konsep sentral karangan dangding Kinanti Ngahurun 
Balung dalam buku, "Empat Sastrawan Sunda Lama" dijelaskan bahwa danding ini menggambarkan mengenai perjalanan seseorang yang sedang kebingungan mencari Tuhannya. Pengalaman seseorang dalam keyakinan bertuhan tidaklah hanya sebatas sampai konsep belaka, tetapi juga harus dialami sebagai sebuah pengalaman (Ekadjati et al., 1994).

Fokus penelitian ini sendiri yaitu menguak makna teologis yang tekandung di dalam dangding tesebut. Arti teologi sendiri yaitu terdiri dua kata yaitu antara Theo dan Logos, Theo berarti Tuhan dan Logos memiliki arti pembicaraan. Dengan begitu dapat dipahami bahwa maksud dari teologi adalah sebuah pembicaraan mengenai Tuhan (Al-Fayyadl, 2012). Secara metodologis, kemudian teologi dibagi ke dalam dua aspek, yaitu teologi sebagai sebuah keyakinan dan teologi sebagai sebuah kajian. Jika dilihat dari teologi sebagai sebuah keyakinan, maka memiliki pengertian sebagai seperangkat dogma yang dianut oleh suatu agama tertentu dan keyakinan tersebut dijalankan oleh para pemeluk agama dengan penuh kesadaran. Berbeda dengan teologi sebagai sebuah keyakinan, teologi sebagai sebuah kajian memiliki arti yaitu teologi yang berkembang pada ranah wacana yang berasal dari hasil penelaahan konsep-konsep mengenai ketuhanan. Sehingga dapat dikatakan bahwa teologi sebagai sebuah kajian lebih bergerak pada ranah epistemologis dan ontologis bukan pada ranah historis sebagaimana pengertian teologi sebagai sebuah keyakinan (AlFayyadl, 2012).

Maka dari itu, penulis di sini menggunakan teologi dalam pengertian yang kedua, yaitu sebagai sebuah kajian. Sehingga makna teologis yang hendak diambil dari dangding Kinanti Ngahurun Balung karya HHM ini adalah makna yang dikandung di dalam dangding tersebut mengenai konsep-konsep ketuhanan yang terekspresikan di dalamnya. Kemudian secara spesifik, pemaknaan teks dangding ini diarahkan pada bentuk teologi negatif. Teologi negatif sendiri adalah teologi yang mencoba menjelaskan ketidaktahuan mengenai Tuhan. Dalam teologi ini, jawaban yang dihadirkan tidak lebih dari dua jawaban yaitu saying not dan not saying. Saying not yaitu mengatakan tidak tahu, dalam artian Tuhan diakui Ada, akan tetapi penuh misteri dan keberadaan-Nya tidak dapat dipikirkan. Sementara not saying yaitu bukan hanya mengatakan ketidaktahuan, akan tetapi juga tidak berkata apapun mengenai Tuhan atau diam (Iswahyudi, 2017). Selain itu, teologi negatif juga di dalamnya memuat beberapa prosedur dalam tatanan epistemologis. Di mana menurut penulis, bait-bait dangding tersebut sesuai dengan tatanan epistemologis yang terdapat di dalam teologi negatif. Prosedur pengetahuan yang dimaksud di antaranya logika negatif, logika kontradiktif dan metaforisitas (Al-Fayyadl, 2012).

Logika negatif adalah logika berpikir yang menempatkan status ontologis sesuatu dalam keadaan selalu ternegasikan oleh sesuatu yang lain 
(Al-Fayyadl, 2012). Sementara, logika paradoks adalah pola berpikir yang meletakkan dua hal yang bertentangan dan saling menegasikan dalam satu pernyataan yang sama dan mengakui kebenaran dua-duanya (Al-Fayyadl, 2012). Dan metaforisitas merupakan kebalikan dari logika analogi, alih-alih mencari persamaan Tuhan dengan yang lainnya, dalam metaforisitas justru lebih menunjuk cara berpikir yang mengandaikan setiap konsep tentang suatu objek selalu mengandung unsur metafor (Al-Fayyadl, 2012).

Dan di sini juga digunakan analisis hermeneutika Paul Ricoeur, yang berangkat dari pemaknaan semantik, kemudian pemaknaan secara reflektif atau fenomenologis dan yang terakhir pemaknaan secara eksistensial atau ontologis (Fithri, 2019). Sebelum memasuki dalam pemaknaan melalui penafsiran tersebut, dalam konstruksi hermeneutik Ricoeur diharuskan untuk mengambil jarak terhadap teks atau dalam istilah Ricoeur disebut dengan distansiasi. Distansiasi ini dilakukan untuk medekontekstualisasi teks, dalam artian membiarkan teks otonom (Hardiman, 2015). Selain distansiasi, kemudian apropsiasi yang mana peran pemahaman penafsir di sini mulai ada terhadap teks. Setelah melakukan apropsiasi, maka akan muncul sebuah horison baru, atau dalam bahasa lain dapat disebut dengan rekontekstualisasi (Ricoeur, 2014). Melalui hermeneutika Paul Ricoeur inilah, penulis berharap dapat menemukan makna teologis baru yang terdapat di dalam dangding Kinanti Ngahurun Balung ini. Terlepas dari pemaknaan-pemaknaan yang sudah ada mengenai kandungan dangding ini.

Maka dari itu, penulis berasumsi bahwa dangding Kinanti Ngahurun Balung ini memiliki makna teologis yang dikandung di dalamnya dengan analisis hermeneutika Paul Ricoeur. Di dalam penelitian ini terdapat satu pertanyaan utama yaitu bagaimana nuansa dan makna teologis yang dikandung dangding Kinanti Ngahurun Balung. Semoga penelitian ini bermanfaat yang kiranya baik untuk menjadi bahan pengetahuan dan diaplikasikan di dalam realitas keberagamaan kini.

\section{Metode Penelitian}

Penelitian ini merupakan jenis penelitian kualitatif dengan menerapkan studi pustaka menggunakan metode analisis hermeneutika Paul Ricoeur. Penelitian dilaksanakan dengan menghimpun sumbersumber kepustakaan, baik yang primer maupun sekunder. Setelah terhimpun, sumber-sumber kepustakaan dikategorikan sesuai pertanyaan penelitian. Setelah dikategorisasikan, penulis melakukan pengambilan data dari sumber pustaka. Data-data tersebut ditampilkan kemudian diabstraksikan yang bertujuan untuk dapat menampilkan fakta. Lalu, fakta tersebut diinterpretasi untuk menghasilkan informasi atau pengetahuan (Darmalaksana, 2020). Pada tahap interpretasi digunakan analisis teori hermeneutika Paul Ricoeur. 
Data primer di dalam penelitian ini yaitu dari buku "Gendingdan Dangding Sunda Katut Wirahmana" diterbitkan oleh Djadjasan Koedjang tahun 1976 yang merupakan salinan dari tulisan Haji Hasan Mustapa. Dan juga buku "Haji Hasan Mustapa: Sufi Besar Tanah Pasundan" yang sama memuat teks dangding Kinanti Ngahurun Balung. Data sekunder merupakan data tambahan yang didapatkan dari sumber-sumber yang memiliki keterkaitan dengan pembahasan-pembahasan di dalam penelitian ini seperti buku, jurnal, dan karya ilmiah yang lainnya.

Adapun beberapa tahapan metode yang dilalui dalam penelitian ini di antaranya: Pertama, kesinambungan historis, di mana tahapan ini, penulis mencoba melakukan pembacaan terhadap latar belakang pikiran pengarang teks dangding Kinanti Ngahurun Balung yaitu Haji Hasan Mustapa. Ada dua bentuk latar belakang: 1) latar belakang eksternal yang meliputi suasana zaman yang dialami oleh HHM seperti segi sosio-politik, ekonomi, budaya, filsafat, sastra dan yang lainnya; dan 2) latar belakang internal yang meliputi riwayat hidup, pendidikan, pengaruh yang diterimanya, hubungan dengan tokoh-tokoh lain dan sebagainya (Bakker \& Zubair, 1990). Kedua, hermeneutika Paul Ricoeur. Pada tahapan ini, setelah tahapan sebelumnya agar mengetahui nuansa teks tersebut, penulis menggunakan hermeneutika Paul Ricouer. Di dalam sistem hermeneutikanya, ada tahapan dalam menginterpretasi sebuah teks, yakni distansiasi terhadap teks atau pengambilan jarak terhadap teks, agar teks menjadi otonom. Setelah itu, apropsiasi teks yaitu teks direkontekstualisasikan oleh penulis dengan konteks kekinian. Pada tahap selanjutnya, masuk pada proses memahami teks: 1) tahapan semantik; 2) tahapan reflektif; dan 3) tahapan eksistensial (Wahid, 2015).

\section{Hasil dan Pembahasan}

\section{Biografi Haji Hasan Mustapa}

\section{a) Latar Belakang Kehidupan Haji Hasan Mustapa}

Haji Hasan Mustapa (HHM) lahir di Garut, pada tanggal 03 Juni 1852. Beliau merupakan keturunan dari keluarga menak dan pesantren. Keturunan menak ini terlihat dari ayahnya yang bernama Mas Sastramanggala, sebagai camat Cikajang saat itu yang memiliki darah keturunan dari bupati Parakanmuncang. Sementara ibunya bernama Nyi Mas Salpah yang merupakan putra dari Mas Ngabehi Kartapraja, di mana kakek dari ibunya tersebut pernah juga menjabat sebagai camat Cikajang juga (Ekadjati et al., 1994). Sementara, darah pesantrennya berasal dari ibunya. Di mana dari jalur ibunya ini, banyak kerabat yang menjadi sosok ulama dan sekaligus guru bagi HHM (Rohmana, 2015).

Di antara guru-gurunya tersebut adalah Mbah Haji Hasan Basri Kiarakoneng untuk belajar al-Qur'an, kemudian belajar tata bahasa Arab 
kepada Raden Haji Yahya Garut, setelah itu belajar kepada Kiai Abdul Hasan Sawahdadap, Kiai Muhammad Cibunut Garut dan belajar kepada beberapa kiai lainnya. Selain itu, HHM juga pernah menimba ilmu di Mekkah. Selama di Mekkah itu, HHM menimba ilmu kepada beberapa guru di antaranya kepada Syekh Muhammad, Syekh Abdulhamid, Syekh Ali Rahbani, Syekh Umar Sani, Syekh Mustomal Apipi, Sayyid Bakri dan Sayyid Abdullah Janawi (Asura, 2020). Semua guru-guru HHM tersebut merupakan sekelompok ulama jaringan nusantara yang dipimpin oleh Syekh Nawawi al-Bantani. Pengalaman didaktis HHM inilah yang melatarbelakangi karya-karya yang kemudian dituliskan oleh beliau sarat akan nilai spiritualitas Islam.

Di dalam dangdingnya yang berjudul Pangkur Pangkurangna Nya, menjelaskan mengenai hubungannya dengan Snouck Hogronje. HHM pernah diminta untuk menemani Snouck mengelilingi Jawa dan Madura, untuk menjadi informan pribumi saat itu. Tugasnya adalah mengumpulkan karya tulis maupun cerita lisan yang ada pada saat itu, yang mana salah satu dari sekian banyak naskah atau teks karya tulis yang dikumpulkannya, ada dua naskah yang menceritakan tentang konsep Martabat Tujuh dan Tarekat Syattariyah (Asura, 2020). Yang mana kedua naskah tersebut, disinyalir sangat memengaruhi karya-karya HHM di kemudian hari, terutama dangding-dangdingnya.

Berkat kedekatannya dengan Snouck Hogranje, HHM ditawari posisi di pemerintahan kolonial Hindia-Belanda saat itu. Atas usulan Snouck, HHM diangkat menjadi penghulu di Kutaraja Aceh selama dua tahun sembilan bulan (1893-1896). Setelah itu, HHM menjadi penghulu di Bandung dari tahun 1896-1917 (Rohmana, 2016). Selama menjadi penghulu di Bandung inilah, HHM banyak menuliskan dangding-dangdingnya dalam kurun dua tahun (1900-1902), yang hampir berjumlah 10.000-an bait dan merupakan dangding terbanyak yang tercatat dalam sejarah kesusastraan Sunda (Setiawan, 2016).

Karya-karya yang kemudian HHM tuliskan, nampaknya banyak dipengaruhi oleh beberapa latar belakang. Selain latar kehidupan pesantren, HHM juga banyak dipengaruhi oleh pemikiran mistisme Islam Nusantara terutama saat HHM menjadi penghulu di Kutaraja Aceh di antaranya seperti Hamzah Fansuri, Syamsuddin al-Sumatrani, Nuruddin al-Raniri dan Abdurrauf al-Sinkili. Selain dipengaruhi oleh dua hal tersebut, HHM juga kemungkinan banyak membaca karya-karya tasawuf seperti pemikiran Ibn Arabi, Abdul Karim al-Jilli, al-Ghazali, dan juga alBurhanfuri. Hal tersebut kemungkinan besar HHM lakukan pada saat ia menimba ilmu di Mekkah selama beberapa tahun (Rohmana, 1991).

Selain itu, sosial-keagamaan yang berkembang saat HHM menjabat penghulu di Bandung sekitar abad ke 19 yang mulai bermunculan gerakangerakan keagamaan modern. Yang mana gerakan-gerakan keagamaan 
tersebut, ingin mengindentifikasi keberagamaannya tersebut dengan ala Timur Tengah. Sementara HHM adalah sosok yang tetap bisa mempertahankan akar kulturalnya sebagai orang Sunda, sekalipun ia memeluk Islam. Hal ini terlihat dari karyanya yang bernuansa sastra sufistik Islam tetapi kebanyakan menggunakan bahasa Sunda, meskipun dalam tulisannya menggunakan tulisan Arab pegon (Rohmana, 1991).

\section{b) Karya Haji Hasan Mustapa}

Karya yang dihasilkan oleh HHM sangat beragam, di antaranya berupa dangding. HHM menulis sebanyak kurang lebih 10.000-an dangding, yang ditulisnya selama kurun waktu dua tahun dan kurang lebih menjadi sekitar 70 judul dangding dengan pupuh yang berbeda-beda. Beberapa karya lain HHM yang berbentuk prosa di antaranya: Bab Adatadat Urang Priangan jeung Urang Sunda Liannta ti Eta; Buku Leutik Pertelaan Adatna Jalma-Jalma di Pasundan; Bale Bandung; Buku Pangapungan; Buku Pusaka Kanaga Warna; Buku Kasauran Panungtungan; Wawarian; Pamalaten; Aji Saka; Syeh Nurjaman; Petikan Qur'an Katut Adab Padikana; Gelar Sasaka di Kaislaman; Istilah; Martabat Tujuh; dan karya-karya lainnya.

\section{c) Pemikiran Haji Hasan Mustapa}

HHM jika dilacak, pemikirannya terpengaruh oleh Ibn Arabi. Terutama mengenai konsep Wahdatul Wujud-nya. Akan tetapi, yang kemudian paling mendominasi adalah pemikiran mengenai Martabat Tujuh. Konsep Martabat Tujuh berawal dari tokoh al-Burhanfuri, dari kitabnya yang berjudul al-Tuhfah al-Mursalah. Dalam beberapa sumber lain pun, bahwa HHM adalah penganut paham tarekat Syattarriyah yang dibai' at oleh Kyai Nurhakim Banyumas. Dan paham Martabat Tujuh yang dikembangkan oleh HHM sangat disinyalir berasal dari tokoh tasawuf yang berasal dari Tasikmalaya yaitu Syaikh Abdul Muhyi Pamijahan (Jahroni, 2018).

Sementara terlihat dari beberapa dangding yang dituliskan oleh HHM, beliau tidak beranjak dari tema suluk. Gagasan yang sama kadang diulangnya kembali pada dangding-dangding tersebut (Rohmana, 1991). Seperti di antaranya pengalaman spiritual yang dialami HHM dituliskan dalam Kinanti Tutur teu Kacatur Batur, Jung Indung Turun Ngalayung, Puyuh Ngungkung dina Kurung, Asmarandana Tadina Aing Pidohir, Kasmaran Dening Hakiki, al-Insanu Sirri, Babalik Pikir, Panorah Rasa, dan Amis Tiis Pentil Majapait serta tentunya Kinanti Ngahurun Balung yang menjadi fokus dalam penelitian ini (Rohmana, 1991).

Seperti yang telah dituliskan sebelumnya, ajaran Martabat Tujuh adalah ajaran yang paling mencolok dalam pemikiran HHM. Selain dalam bentuk danding, pemikiran HHM mengenai hal tersebut juga terdapat dalam teks-teks biasa seperti dalam Gelar Sasaka dina Kaislaman dan Adji 
Wiwitan Martabat Tujuh (Rohmana, 2020). Hal ini tidak lepas dari pengaruh guru-guru HHM, baik selama belajar di tanah Sunda dan juga di Mekkah. Selain itu, juga tidak terlepas dari kedekatannya dengan Snouck Hogranje yang pernah mengajaknya berkeliling dua kali Jawa-Madura dan pengalamannya menjadi penghulu selama di Aceh (Rohmana, 2020).

Martabat Tujuh sendiri adalah sebuah paham mengenai proses mewujudnya Tuhan atau manifestasi Tuhan melalui tujuh tingkatan emanasi. Secara singkat, pemikiran HHM terutama mengenai Martabat Tujuh digambarkan dalam dangding yang bejudul Pucung Lutung Buntung Naek Kana Pager Gintung (Rohmana, 2020). Di dalam dangding tersebut dijelaskan bahwa tujuh martabat tadi terbagi dua, yaitu tiga tingkatan ada pada Tuhan di antaranya alam ahadiyat, wahdat, dan wahidiyat. Sementara sisanya ada pada mahkluk, di antaranya alam arwah, mitsal, ajsam dan kainsanan (Rosidi, 1989). Pemikiran mengenai Martabat Tujuh ini tidak jauh berbeda dengan tokoh-tokoh sebelumnya seperti al-Burhanfuri dan Syeikh Abdul Muhyi Pamijahan, hanya saja HHM melakukan pengejawantahan paham tersebut kerap menggunakan idiom-idiom khas Sunda.

\section{Gambaran Dangding Kinanti Ngahurun Balung}

Secara umum, konsep yang menjadi sentral karangan dari dangding Kinanti Ngahurun Balung menurut buku yang berjudul "Empat Sastrawan Sunda Lama" adalah menceritakan pengalaman religius seseorang yang sedang mencari Tuhannya. Dangding Kinanti Ngahurun Balung ini terdiri dari 109 bait, dan tiap baitnya terdiri dari 6 baris. Dangding ini dibuka dengan bait (Jajasan Kudjang Bandung, n.d.) :

Tungtungna ngahurun balung
gurubukur malar bukti
rek nyaba jeung Allah saha
kacapangan Ya Ilahi
he Allah Gusti kaula
di nu negrak di nu suni
akhirnya duduk melamun guru intinya untuk bukti mau pergi dengan Allah siapa jadi omongan ya Ilahi wahai Allah Gusti kami di tempat terbuka dan tersembunyi

Dari bait ini, digambarkan bagaimana pengalaman HHM yang sedang mencari Tuhan dengan posisi "ngahurun balung" atau memeluk kaki seperti orang yang kebingungan. Proses pencarian Tuhan bukan menjadi terang, akan tetapi akan semakin bingung, jika seseorang yang sedang mencari tersebut berada di posisi yang mengambang dan tidak seimbang. Posisi ini dikarenakan pengetahuan seseorang yang kurang terbuka, sehingga memiliki pemahaman yang sempit. Akibat dari pemahaman yang seperti itu, akan menimbulkan sikap yang fanatik atau dalam istilah yang digunakan oleh HHM adalah "tutuh mikukuh" (Ekadjati et al., 1994). Seperti 
yang digambarkan dalam bait yang ketiga dalam dangding Kinanti Ngahurun Balung ini:

Mupunjung ka uwung-uwung

Migusti ka katumbiri

Mangeran ka awang-awang

Lain deui lain deui

$\mathrm{Nu}$ aya disaha-saha

Aling-aling roh idopi memuja-muja langit jauh menuhankan pada pelangi menganggap Tuhan ke angkasa bukan lagi bukan lagi yang ada ditanyai sebagai siapa penghalang roh idlofi

Dalam bait yang ketiga ini, digambarkan bagaimana seseorang yang sedang kebingungan tersebut selalu menganggap hal-hal yang lain sebagai Tuhan. Kebimbangan seseorang yang sedang dalam pencarian tersebut, dijawab oleh HHM di dalam bait ke 47:
Heung iwung sebutkeun iwung Heug awi sebutkeun awi
Kajeun ceuk dengen mah loba
Teu nyahoeun barang hiji
Hiji dua tilu opat
Hijina tina mimiti
kalau rebung katakan rebung kalau bambu katakan bambu sekalipun kata yang lain banyak tak mengetahui barang satu satu dua tiga empat satu itu dari awal

Dalam dangding ini, HHM memberikan jawaban sikap yang harus diambil ketika seseorang tersesat atau kebingungan dalam pencarian Tuhan. Yaitu kita harus pintar mencari asal usul dan harus juga mengenali sosok yang pertama. Sikap fanatik atau "tutuh mikukuh" yang diungkapkan HHM sebagai bentuk pemahaman seseorang yang sempit juga, dituliskan dalam dangding kinanti Ngahurun Balung bait ke 23.

\section{Numatak disebut tukuh \\ Tara salin ti sasari \\ Tara jeung pangaweruhna \\ Cicing dina alam hiji \\ Tara ditanya ka mana \\ Lamun aing henteu indit}

\author{
makanya disebut teguh \\ tak pernah berganti baju biasanya \\ tak pernah dengan ilmunya \\ diam di alam satu \\ tak pernah ditanya kenapa \\ kalau aku tidak pergi
}

Di dalam bait dangding yang lain di Kinanti Ngahurun Balung ini juga, HHM menggambakan sikap lain yang harus dimiliki oleh seseorang yang sedang melakukan pencarian. Bunyi bait tersebut seperti ini:

Katuhu paranti nyatu

Kenca paranti susuci

Mulya hina duanana kanan peralatan makan

kiri peralatan bersuci

mulia hina pada berpasangan 
Milik aing nu sajati

Mun aing beurat sabeulah

Tanda ning ngalain-lain milik saya nan sejati

kalau saya berat sebelah

tanda membukan dan lain

Pada akhirnya, di bait-bait akhir. Semua pengalaman pencarian ketuhanan yang ditempuh seseorang tersebut harus mencapai pada titik di mana menyebut Tuhan bukan hanya sekedar penyebutan biasa, melainkan berdasarkan atas perjalanan pengalaman yang benar-benar dialami. Hal ini digambarkan dalam bait yang ke 106 dan 107 (Jajasan Kudjang Bandung, n.d.).

Iraha ngalandi sintung Lamun buktina ngan kitri Iraha gumelar hayam Lamun jalma sakabeuki Endog ulah sina megar

Da bongan make dipeuncit

Iraha timbulna suung

Lamun taya musim ngijih

Iraha gumelar supa

Lamun taya catang kai

Iraha nelah kaula

Lamun taya bibit gusti kapan menyebut sintung kalau buktinya hanya kitri kapan lahirnya ayam kalau manusia satu kegemaran telur jangan disuruh menetas salah sendiri kenapa disembelih

kapan munculnya jamur kalau tak ada musim penghujan kapan munculnya supa kalau tak ada kayu busuk kapan disebut saya kalau tidak ada bibit Gusti

Beberapa idiom-idiom yang digunakan HHM di dalam dangding ini sarat akan nuansa kesundaan. Misalnya penggunakan kata sintung dan kitri, endog (telur) dan hayam (ayam), suung (jamur) dan musim penghujan, supa dengan kayu busuk serta beberapa idiom lain yang juga terdapat dalam dangding-dangding HHM lainnya. Di mana penggunakan kata tersebut sebagai simbol mengenai relasi Tuhan dengan mahkluk.

Secara umum, begitu gambaran hal yang menjadi pembicaraan dalam Kinanti Ngahurun Balung ini. Yang didasarkan pada pemahaman setiap bait di dalam dangding tersebut, dan dihubungkan pada aspek keilmuan dan sosio-kultural dari HHM sendiri. Namun kemudian, pada pembahasan selanjutnya, penulis mencoba mencari makna baru dengan menggunakan pendekatan hermeneutika Ricoeur, yang mengharuskan teks otonom dan penulis terbuka kepada teks sehingga memungkinkan ditemukannya makna baru. 


\section{Analisis Makna Teologis Dangding Kinanti Ngahurun Balung}

\section{a) Distansiasi dan Apropsiasi terhadap Teks Kinanti Ngahurun Balung}

Langkah awal yang diambil dalam penafsiran teks dangding Kinanti Ngahurun Balung ini adalah dengan distansiasi atau pengambilan jarak terhadap teks. Pengambilan jarak yang dilakukan terhadap teks ini dimaksudkan agar penulis tidak terjebak di dalam maksud HHM, situasi sosio-kultural teks pada saat dangding ini dituliskam dan maksud yang ditujukan HHM di dalam teks dangding Kinanti Ngahurun Balung. Sehingga teks dangding Kinanti Ngahurun Balung ini menjadi otonom dan terbuka untuk dibaca oleh siapapun (Pamungkas, 2016).

Teks harus sedimikian rupa dibebaskan, sehingga yang tersisa hanyalah teks dangding tersebut yang terbuka. Hal ini juga disebut dalam istilah lain sebagai dekontekstualisasi teks. Inilah merupakan langkah pertama yang harus dilakukan untuk memahami teks dangding. Setelah teks tersebut terbuka karena telah otonom, maka pada akhirnya ia dimungkinkan untuk dibaca secara luas dengan pembaca yang berbedabeda terutama oleh penulis (Sumaryono, 1999).

Dalam hal ini, seperti yang telah dituliskan sebelumnya yaitu mengenai biografi HHM, karya-karya dituliskan dan pemikiran yang memengaruhi HHM, hal tersebut harus dilepaskan sehingga menjadikan teks dangding Kinanti Ngahurun Balung otonom. Pada tahapan ini, penulis mencoba untuk melepaskan teks dari kecenderungan tersebut. Bahwa teks dangding ini harus terbuka dan terlepas dari fakta-fakta yang membuktikan bahwa HHM sebagai penganut paham Wahdatul Wujud, lingkungan yang melingkupi teks pada saat itu dan maksud dari HHM untuk siapa teks dangding yang dibuatnya ditujukan.

Setelah sebelumnya melakukan pengambilan jarak terhadap teks dangding Kinanti Ngahurun Balung, kemudian adalah penulis mulai masuk untuk memahami teks dangding Kinanti Ngahurun Balung. Di sini penulis kemudian harus bisa merekontekstualisasi teks sesuai dengan konteks kekinian. Penulis harus menjadikan teks dangding Kinanti Ngahurun Balung sebagai miliknya sendiri, setelah sebelumnya teks dilepaskan dari maksud pengarang, situasi sosio-kultural dan kepada siapa teks ditujukan, sehingga teks menjadi otonom (Wahid, 2015).

Setelah itu, teks dangding Kinanti Ngahurun Balung dipijakan penulis untuk mengungkapkan makna teologis yang terdapat di dalam teks tersebut. Akan tetapi, teks dangding ini bukan berarti mengungkapkan makna teologis yang dikandung di dalamnya dengan sendirinya, melainkan bagaimana teks dangding terbuka untuk dimaknai oleh penulis dan dari pembacaan terhadap teks dangding ini diharapkan mendapatkan makna teologis yang baru. Pada intinya, kemudian adalah bagaimana teks Kinanti Ngahurun Balung masuk ke dalam pembaca dan teks menjadi titik 
tolak pemaknaan yang dilakukan oleh pembaca atau penulis dalam konteks penelitian ini. Dengan begitu, makna baru dari teks tersebut akan didapatkan.

\section{b) Nuansa Teologis Dangding Kinanti Ngahurun Balung}

Nuansa pemikiran teologis yang dikandung di dalam teks dangding Kinanti Ngahurun Balung ini, dapat terlihat dari beberapa simbol dan metafora yang digunakan. Dalam dangding ini banyak baitnya yang menggambarkan nuansa teologis, baik itu secara implisit maupun eksplisit. Namun, dari keseluruhan 109 bait yang terdapat di dalam dangding Kinanti Ngahurun Balung, tidak semuanya menggambarkan aspek nuansa teologis. Ada beberapa yang lebih pada hal kepribadian HHM dan penggambaran kondisi saat HHM hidup.

Seperti misalnya, dalam bait pertama. Ada ungkapan "rek nyaba ka Allah saha, kacapangan ya Ilahi, he Allah gusti kaula, di nu negrak di nu suni"(Jajasan Kudjang Bandung, n.d.). Di sini secara eksplisit, ada ungkapan yang bernuansa teologis. Yang terlihat dari penggunaan kata Allah dan Ilahi di sana. Juga pada bait ke lima, "babasan Allah nu Agung, waspada lahir jeung batin, marukan lain nyaeta, lahirna dituding ati, batinna ditorah rasa, moal salahir sabatin"(Jajasan Kudjang Bandung, n.d.). Sama seperti pada bait pertama, ungkapan teologis secara jelas disebutkan di sini.

Lain hal di dalam bait yang lainnya. Secara implisit menggunakan bahasa Sunda yang simbolis, nuansa teologis dituangkan dalam dangding ini begitu banyak. Seperti dalam bait ke sembilan, "beh di kaler beh di kidul, saha deui saha deui, nu mana mayar maana, aing deui aing deui, ngambang di sagara mangmang, manggih lain manggih lain"(Jajasan Kudjang Bandung, n.d.). Dibait selanjutnya, "tah kitu yataroddadun, da bongan piraebihim, katambias parahuna, kerok miriwinci hiji, ngumbara sosorangan, da puguh pahatu lalis"(Jajasan Kudjang Bandung, n.d.). Di sini secara implisit menggambarkan pencarian Tuhan, nuansa teologis begitu kuat dengan ungkapan "kerok miriwinci hiji" keliru memerinci satu.

Secara simbolik, nuansa teologis lain yang dikandung dangding ini digambarkan dengan penggunaan idiom-idiom khas Sunda. Seperti pada bait ke empat puluh tujuh, "heug iwung sebutkeun iwung, heug awi sebutkeun awi, kajeun ceuk deungeun mah loba, teu nyahoeun barang hiji, hiji dua tilu opat, hijina tina mimiti"(Jajasan Kudjang Bandung, n.d.). Di sini yang menjadi perhatian adalah penggunaan kata "iwung" dan "awi", yang sepertinya secara simbolik memiliki keterikatan sebagai bentuk relasi sebab-akibat. Dan banyak idiom yang lainnya, yang akan dibahas pada bagian selanjutnya. 


\section{c) Makna Teologis Dangding Kinanti Ngahurun Balung}

Sebelumnya telah dituliskan beberapa bait dalam dangding Kinanti Ngahurun Balung ini yang secara harfiah mengandung nuansa teologis, yang hal tersebut merupakan langkah awal penulis mengasumsikan bahwa teks ini mengandung makna teologis di dalamnya. Begitu juga dihadirkan beberapa idiom yang digunakan HHM sebagai sebuah simbol dan metafora untuk menggambarkan bentuk-bentuk keyakinan teologis HHM yang temuat di dalam dangding ini. Ada beberapa tahapan yang digunakan untuk dapat memahami sebuah teks. Maka dari itu, penulis mencoba menghadirkan makna sementara yang dimaksudkan oleh HHM. Yang berasal dari beberapa sumber yang membahas teks dangding Kinanti Ngahurun Balung dan juga berasal dari pembacaan pertama penulis atas teks tersebut.

Pada tahapan selanjutnya, penulis mencoba menguak makna teologis baru yang terdapat di dalam teks dangding Kinanti Ngahurun Balung. Hal tersebut bukan berarti penulis memasukkan pemahaman-pemahaman yang dimiliki ditempelkan terhadap teks dangding ini, melainkan bagaimana teks terbuka dan masuk kepada penulis. Dengan begitu, teks tersebut menjadi pijakan untuk mendapatkan makna teologis yang disesuaikan dengan konteks penulis, sehingga teks tidak menjadi ahistoris dan terus hidup (Wahid, 2015).

Pada bait pertama dangding yang berbunyi "tungtungna ngahurun balung, guru bukur malar bukti, rek nyaba ka Allah saha, kacapangan ya Ilahi, he Allah Gusti kaula, di negrak di nu suni"(Jajasan Kudjang Bandung, n.d.). Di dalam bait ini jelas, bahwa dalam proses pencarian Tuhan, seseorang perlu untuk merenungkannya dengan begitu serius dan mendalam. Sebagaimana yang digambarkan secara simbolik di dalam bait tersebut dengan kata "ngahurun balung" yang jika diartikan adalah kondisi seseorang yang sedang merenung dengan posisi memeluk kakinya. Akan tetapi, kegiatan tersebut bukan hanya kegiatan merenung saja. Melainkan harus dibarengi dengan pengetahuan yang mumpuni, sehingga didapatkan perenungan yang benar dan tidak asal-asalan.

Pada bait ketiga yang berbunyi "mupunjung ka uwung-uwung, migusti ka katumbiri, mangeran ka awang-awang, lain deui lain deui, nu aya disaha-saha, aling-aling roh idlofi" (Jajasan Kudjang Bandung, n.d.). Sikap teologis (dalam artian sebagai sebuah kajian) kita, seringkali dangkal dan tak mendalam. Keyakinan terhadap Tuhan selalu tidak tepat, karena diarahkan pada sosok yang salah. Selalu ada upaya mempersonifikasikan Tuhan, sehingga kebanyakan menimbulkan keyakinan bahwa Tuhan baru akan dapat diyakini jika Dia dapat dibayangkan. Seperti salah satu baris dalam bait yang kedua "nuding kanu lain-lain," pada akhirnya sikap tersebut hanya akan menimbulkan praduga saja atas apa yang diyakini sebagai Tuhan. 
Pada bait ke delapan dan sembilan "kasarung turut lulurung, balik deui balik deui, sabab dina sisimpangan, balik deui balik deui, midangdam neangan Allah, lain deui lain deui. Beh di kaler beh di kidul, saha deui saha deui, nu mana mayar maana, aing deui aing deui, ngambang di sagara mangmang, manggih lain manggih lain" (Jajasan Kudjang Bandung, n.d.). Berangkat dari bait ini, kenyataan pencarian Tuhan selalu menemukan titik kebingungan seperti yang digambarkan dalam kalimat "ngambang di sagara mangmang" mengambang di lautan kebimbangan/keragu-raguan (Satjadibrata, 2019). Selain itu, kebingungan dalam pencarian Tuhan terdapat dalam bait sesudahnya, di mana dalam bait tersebut ada kata Yatarddadun yang mana kata tersebut berasal dari bahasa Arab berbentuk fiil mudhori jamak dan memiliki arti bimbang (Munawwir, 2002). Ada juga kata "piraebihim" yang merupakan kata berbahasa Arab, arti kata tersebut kira-kira seperti ini “dalam keraguan mereka” (Asura, 2020).

Di dalam bait ketiga belas, ada ungkapan "kalingkung ku bingung kitu" terkurung oleh rasa bingung. Dan pada bait ke empat belas "bukurna nu dipibingung, pahili ku barang hiji" buktinya yang dibingungkan, tertukar oleh barang yang satu dan "lawas kalindih panglandi"lama terkalahkan nama panggilan. Sama dengan bait sebelumnya, bahwa pada kenyataannnya, kita akan terkurung dalam rasa bingung. Kebingungan tersebut disebabkan karena Tuhan yang kita cari, telah tersamarkan oleh sebutan-sebutan yang kita sematkan pada-Nya.

Rasa bingung dan bimbang juga, digambarkan dalam bait ke tiga puluh dua, "di dieu hayang ka ditu, di ditu ka dieu deui"(Jajasan Kudjang Bandung, n.d.) dari sini ingin ke sana, dari sana ke sini lagi. Dari penggalan bait tersebut, proses pencarian yang membingungkan tersebut seperti menemukan jalan yang memutar. Ketika mencoba berusaha untuk mencari, alih-alih menemukan, yang ada kita kembali ke posisi awal yaitu diselubungi oleh kebingungan. Apakah pada akhirnya usaha untuk mencari Tuhan akan berakhir sia-sia.

Penulis kemudian menemukan di bait-bait lainnya, yang bisa menjadi jawaban dari bait-bait yang sebelumnya memperlihatkan sebuah perjalanan membingungkan dan tak ada ujung dalam pencarian Tuhan. Pada bait-bait yang lain, banyak digunakan idiom-idiom khas Sunda. Seperti iwung (rebung)(Satjadibrata, 2019) dengan awi (bambu), kalapa (kelapa) dengan kitri (bibit kelapa), pare (padi) dan beas (beras)(Satjadibrata, 2019), idiom-idiom khas Sunda tersebut merupakan bentuk simbol dan metafora yang terdapat dalam dangding. Dapat dipahami bahwa sebenarnya semua berasal dari entitas yang satu yaitu Tuhan. Sekilas idiom tersebut memperlihatkan relasi antara Tuhan dengan makhluknya. Dengan begitu, pencarian akan Tuhan tidak perlu dilakukan dengan jauh-jauh pada hal yang lain. Karena sejatinya, kita berasal dari Tuhan yang kita cari. Kebingungan-kebingungan yang dialami selama proses pencarian Tuhan, 
disebabkan kita mencarinya jauh di luar diri kita dengan konsep-konsep yang dilekatkan terhadap Tuhan itu sendiri.

Hal tersebut ditegaskan kembali di dalam bait ke 107 "Iraha timbulna suung, lamun teu aya musim ngijih, iraha gumelar supa, lamun taya catang kai, iraha nelah kaula, lamun taya bibit gusti" (Jajasan Kudjang Bandung, n.d.). Munculnya jamur karena ada musim hujan, munculnya supa (sejenis jamur juga) karena ada kayu yang busuk, dan adanya manusia karena adanya Tuhan. Bait ini, bagi penulis bukanlah bentuk prinsip kausalitas atau sebabakibat, melainkan kedekatan Tuhan dengan kita sebagai makhluk yang sedang mencarinya. Dengan kenyataan yang sangat begitu dekat itu, kita tak akan pernah mendapatkan pengetahuan dengan konsep-konsep yang kita bawa dan lekatkan pada hal yang kita asumsikan sebagai Tuhan. Pada akhirnya, Tuhan hanya bisa dirasakan kehadirannya, bukan dipikirkan sebagaimana konsep yang kita sematkan.

Proses pencarian Tuhan berangkat dari pijakan pembacaan terhadap dangding Kinanti Ngahurun Balung ini, yang di dalamnya memuat kebingungan-kebingungan dalam proses pencarian Tuhan, justru dapat dikatakan menawarkan sebuah bentuk baru cara berteologi. Yaitu bentuk teologi negatif (Al-Fayyadl, 2012) atau dalam istilah lain juga disebut dengan teologi apofatik (Iswahyudi, 2017). Dalam dangding ini, jawaban yang dihadirkan tidak lebih dari dua jawaban yaitu saying not (mengatakan tidak tahu, dalam artian Tuhan diakui Ada, akan tetapi penuh misteri dan keberadaan-Nya tidak dapat dipikirkan) dan not saying (tidak berkata apapun mengenai Tuhan atau diam)(Al-Fayyadl, 2012).

Jika didasarkan pada dangding Kinanti Ngahurun Balung, beberapa baitnya menyiratkan bentuk logika negatif. Misalnya yang terdapat dalam bait ke 2 dan ke 3 ada ungkapan "nuding kanu lain-lain" dan "lain deui lain deui." Ketika kita berusaha mengetahui Tuhan sedemikian rupa, pada akhirnya kita akan menemukan kesimpulan bahwa Tuhan bukanlah sesuatu yang telah kita anggap diketahui. Anggapan-anggapan yang coba disematkan pada Tuhan, selalu berujung pada kenyataan bahwa Tuhan tidak seperti yang dipikirkan atau dikonsepkan. Pada akhirnya hanya menuduh pada yang bukan Tuhan itu sendiri dan juga berakhir pada bukan lagi bukan lagi.

Selanjutnya dalam bait dangding yang ke 60 dan 63, "mun teu macul moal nyatu, teu ka cai moal mandi, mun euweuh kejo teu nangan, mun teu ngarah moal ngarih, mun sangsara paeh bangke, mun teu ngulik moal mukti." Pada bait ke 60, tersebut seperti mengungkapkan prinsip kausalitas. Di satu sisi, bait ke 63 memberikan jawaban yang berbeda dan bertolak belakang dengan prinsip kausalitas "teu macul teu burung nyatu, paeh titeuleum keur mandi, teu nangan kemerkaan, teu ngarah teu burung ngarih, babatan menang jatnika, mucigrig bawaning ngulik." Berangkat dari kedua bait tersebut, ada dua kenyataan yang paradoksal. Di satu sisi kita meyakini bahwa dengan kita 
berkehendak, sesuatu itu akan kita dapatkan, di mana hal tersebut sesuai dengan prinsip kausalitas. Di sisi lain, memiliki kenyataan yang berbeda dan tentu bertolak belakang dengan prinsip kausalitas. Sekalipun tidak ada usaha untuk mendapatkan sesuatu, bisa saja kita mendapatkan sesuatu yang diusahakan sebagaimana yang tertulis dalam bait ke 60 .

Dangding sebagai sejenis puisi sudah barang tentu mengandung simbol dan metafora, seperti yang telah penulis tuliskan mengenai beberapa idiom yang terdapat di dalam dangding Kinanti Ngahurun Balung. Seperti misalnya, antara padi dengan beras, bibit kelapa dengan kelapa, dan rebung dengan bambu. Dalam metaforisitas, di satu sisi idiom tersebut sebagai sebuah simbol relasi Tuhan dengan makhluk-Nya. Tetapi di dalamnya hal tersebut bukan berarti bahwa relasi tersebut ajeg seperti itu, karena metaforisitas yang dibangun dalam bait itu hanya bersifat sementara dan menduga-duga.

Seperti dalam dangding bait ke 44 dituliskan "tah hartina ilallahu, lain di iwung lain di awi, iwung tara teu awian, duwegan kudu ti kitri, tara beas teu parean, awi runtag ku panglandi"(Jajasan Kudjang Bandung, n.d.). Dalam bait ini menegaskan posisi metaforisitas, bahwa kenyataannya Tuhan tidak benar-benar terletak pada relasi sebagaimana rebung dengan bambu, kelapa dengan bibitnya dan padi dengan beras. Karena semua itu masih tetap mengandung ambiguitas makna dan juga sekaligus ketidakmemadaian yang dikandung di dalamnya, sebagaimana dipertegas di akhir bait tersebut "awi runtag ku panglandi" bambu runtuh karena sebutan (Satjadibrata, 2019).

Pada akhirnya, dari semua bait yang mengandung makna teologis. Dapat dipahami bahwa berdasarkan dangding Kinanti Ngahurun Balung ini, penawaran bentuk keyakinan teologis baru yakni bentuk teologi negatif. Sebesar apapun usaha manusia untuk mengetahui Tuhan, pada akhirnya akan dihadapkan dengan sebuah kondisi kebingungan yang tak berujung, ketidaktahuan akan sosok Tuhan itu sendiri. Namun patut digarisbawahi, bukan berarti usaha pencarian Tuhan adalah hal yang sia-sia. Karena ketidaktahuan sebelum pengetahuan berbeda dengan ketidaktahuan setelah pengetahuan (unknowing after knowing) (Al-Fayyadl, 2012).

Dalam bahasa lain, jika dihadapkan dengan Tuhan, kita akan mengalami pasivitas pengetahuan. Yang memiliki artian, sebuah kondisi di mana manusia menyadari batas-batas pikiran dalam usahanya untuk mengetahui Tuhan, sekaligus keterbukaan akan kemungkinankemungkinan yang baru (Al-Fayyadl, 2012). Karena itu pembicaraan Tuhan harus ditempatkan pada sebuah keadaan penuh kesadaran akan keterbatasan manusia atas pemahaman Tuhan yang transenden. Tuhan harus dilepaskan dari kategorisasi-kategorisasi yang dilekatkan terhadapNya (Muzairi, 2017). Sekalipun manusia tak bisa mengetahui Tuhan, karena keterbatasannya tersebut, di satu sisi saat seperti itu merupakan 
keadaan di mana terjadinya penerimaan pengetahuan baru bahwa manusia tidak mengetahui apapun tentang Tuhan dan bersikap pasrah terhadap apapun yang diberikan oleh Tuhan kepadanya. Bagaimana pada akhirnya manusia sebagai makhluk dapat bersikap rendah diri di hadapan Tuhan dan menyadari keterbatasan kita sebagai hamba serta berpasrah kepadaNya. Jika ditarik pada konteks keberagamaan kini, implikasi dari hal tersebut adalah terciptanya sikap yang inklusif terhadap sesama pemeluk agama terutama Islam, yang dapat diketahui secara historis bahwa pertentangan-pertentangan teologis telah terjadi begitu lama dan tak berujung. Alih-alih merasa paling mengetahui Tuhan, yang ada jutsru sikap kerendahhatian sebagai sama-sama hamba yang merindu pada Tuhannya.

\section{Kesimpulan}

Sebagai makhluk yang memiliki hasrat untuk mengetahui Tuhannya, maka manusia selalu berusaha melakukan usaha apapun untuk menggapai pengetahuan akan Tuhan. Seperti yang penulis lakukan dengan mencari makna teologis yang terkandung di dalam teks dangding Kinanti Ngahurun Balung. Ada dua hal yang penulis temukan dalam dangding Kinanti Ngahurun Balung ini. Pertama, dangding ini secara eksplisit maupun implisit menggambarkan nuansa teologis di dalamnya. Kedua, kebingungan-kebingungan tak berujung dalam pencarian pengetahuan akan Tuhan yang digambarkan di dalam dangding ini, menghasilkan bentuk dan cara berteologi atau mendekati Tuhan secara baru, yakni teologi negatif. Penulis menyadari masih banyaknya dangding yang dituliskan Haji Hasan Mustapa yang sangat layak untuk diteliti. Dan penulis berharap penelitian ini bermanfaat bagi khazanah keilmuan terutama dalam ranah teologi dan filsafat. Penulis merekomendasikan penelitian lebih lanjut dan mendalam, terutama bagi para pengkaji teologi dan filsafat khususnya bidang hermeneutika. Karena disadari bahwa tidak ada makna yang final dalam setiap teks, sebagaimana yang terdapat dalam sistem hermeneutika Ricoeur bahwa teks terus terbuka untuk dimaknai.

\section{Daftar Pustaka}

Al-Fayyadl, M. (2012). Teologi Negatif Ibn Arabi : Kritik Metafisika Ketuhanan. Lkis Yogyakarta.

Asura, E. R. (2020). Haji Hasan Mustapa: Sufi Besar Tanah Pasunda. Penerbit Imania.

Bakker, A., \& Zubair, A. H. (1990). Metodologi Penelitian Filsafat. PT. Kanisius.

Darmalaksana, W. (2020). Cara Menulis Proposal Penelitian. Fakutas Ushuluddin UIN Sunan Gunung Djati Bandung.

Ekadjati, E. S., Hardjasaputra, A. S., Anggawisastra, A. K., Madsuki, A., \& 
Rosyadi. (1994). Empat Sastrawan Sunda Lama. In Departemen Pendidikan dan Kebudayaan.

Fithri, W. (2019). Kekhasan Heremeneutika Paul Ricoeur. TAJDID : Jurnal Ilmu Keislaman Dan Ushuluddin, 17(2), 187-211. https:/ / doi.org/10.15548/tajdid.v17i2.125

Hanafi, A. (2015). Teologi Islam: Ilmu Kalam. PT. Bulan Bintang.

Hardiman, F. B. (2015). Seni Memahami : Hermeneutik dari Schleiermacher sampai Derrida. Penerbit PT Kanisius.

Iswahyudi. (2017). Pengaruh Filsafat terhadap Heterodoksi Teologi Islam. Al-Tahrir, 17, 1-23.

Jahroni, J. (2018). Book review: Menemukan Haji Hasan Mustafa (18521930). Studia Islamika, 25(2), 405-422. https:/ / doi.org/10.15408/sdi.v25i2.8974

Jajasan Kudjang Bandung. (n.d.). Gendingan Dangding Sunda Birahi katut Wirahmana. Jajasan Kudjang Bandung.

Munawwir, A. W. (2002). Al-Munawwir Kamus Arab - Indonesia. Penerbit Pustaka Progressif.

Muzairi. (2017). Diskursus Mengenai Tuhan di Dalam dan di Luar Metafisika (God is Being and God without Being). Refleksi, 17(1), 1-22.

Pamungkas, G. (2016). Distansiasi dan Apropsiasi dalam Hermeneutika Sebuah Tinjauan Hermeneutika Paul Ricoeur. November, 67-77.

Ricoeur, P. (2014). Teori Interpretasi. IRCiSoD.

Rohmana, J. A. (1991). Sastra Sufistik Sunda Dan Peneguhan Identitas Islam Lokal : Kontribusi Dangding Haji Hasan. 22-51.

Rohmana, J. A. (2015). Asmarandana Ngagurit Kaburu Burit: Pengalaman Didaktis Kepesantrenan Haji Hasan Mustapa(1852 - 1930). 4(2), 1.

Rohmana, J. A. (2020). Tasawuf Sunda dan Warisan Islam Nusantara: Martabat Tujuh dalam Dangding Haji Hasan Mustapa (1852-1930). Buletin Al-Turas, 20(2), 259-284.

https://doi.org/10.15408/bat.v20i2.3760

Rohmana, J. A. (2016). Persahabatan Penjajah dan Bangsa Jajahan di Hindia Belanda: C. Snouck Hurgronje dan Haji Hasan Mustapa. Afkaruna: Indonesian Interdisciplinary Journal of Islamic Studies, 12(2), 144-168. https:// doi.org/10.18196/aiijis.2016.0060.144-168

Rosidi, A. (1989). Haji Hasan Mustapa jeun Karya-karyana. Penerbit Pustaka Bandung.

Satjadibrata, R. (2019). Kamus Basa Sunda (Cetakan ke). PT. Kiblat Buku Utama.

Setiawan, H. (2016). Dangding Mistis Haji Hasan Mustapa. 1-29.

Sumaryono, E. (1999). Hermeneutik: Sebuah Metode Filsafat. PT. Kanisius. Wahid, M. (2015). Teori Interpretasi Paul Ricoeur. PT. Lkis. 